\title{
Características físico-químicas do queijo Minas Frescal comercializados em feiras livres da cidade de Montes Claros, Minas Gerais
}

\author{
Handray Fernandes de Souza1*, Gabriel Sthefano Lourenço Pereira ${ }^{2}$, Fernanda Guimarães ${ }^{3}$, Lílian Ferreira \\ Neves $^{4}$, Sandro Braga Soares ${ }^{5}$, Bruna Mara Aparecida de Carvalho ${ }^{6}$, Igor Viana Brandi ${ }^{7}$
}

\begin{abstract}
Resumo
O queijo Minas Frescal representa a maioria dos queijos comercializados em feiras e mercearias em consequência do alto rendimento na fabricação e preço acessível à população. Diante disso, o objetivo com este trabalho foi avaliar as características físico-químicas deste queijo comercializado em feiras livres na cidade de Montes Claros, Norte de Minas Gerais. Após a coleta de queijos em cinco diferentes feiras, foram avaliadas as características referentes ao pH, acidez, umidade, proteína e gordura. Observou-se falta de padronização na produção associada a variação nos teores de umidade (32,62 a 54,06\%), proteínas (34,21 a 49,43\%) e gordura no extrato seco $(41,30$ a $58,41 \%)$. Em relação aos valores de $\mathrm{pH}$ e acidez dos produtos, a temperatura de armazenamento pode torná-los mais ácidos em consequência do tempo de exposição nos locais de venda. Conclui-se que a aplicação de procedimentos operacionais e tecnológicos adequados pode melhorar a qualidade dos produtos, cuja maior procedência é artesanal.
\end{abstract}

Palavras-chave: Norte de Minas Gerais. Produção queijeira. Produção artesanal. Derivado do leite.

\section{Physico-chemical characteristics of Minas Frescal cheese marketed in fairs of the city Montes Claros, Minas Gerais}

\begin{abstract}
The Minas Frescal cheese represents the majority of cheeses marketed in fairs and grocery stores as a consequence of their high production yield and affordable price for the population. Therefore, the objective of this work was to evaluate the physico-chemical characteristics of this cheese marketed in fairs in the city of Montes Claros, North of Minas Gerais. After the cheese collection in five different fairs, the characteristics related to $\mathrm{pH}$, acidity, moisture, protein and fat were evaluated. There was a lack of standardization in production associated with variation in moisture contents (32.62 to 54.06\%), proteins ( 34.21 to $49.43 \%$ ) and fat in the dry extract ( 41.30 to $58.41 \%)$. In relation to the $\mathrm{pH}$ values and acidity of the products, the storage temperature can make them more acidic in consequence the time of exposure in the places of sale. It has concluded that the application of adequate operational and technological procedures can improve the quality of products, whose greater origin is handmade.
\end{abstract}

Keywords: North of Minas Gerais. Cheese production. Artisanal production. Derived from milk.

\footnotetext{
${ }^{1}$ Universidade Federal de Minas Gerais. Instituto de Ciências Agrárias - MG http://orcid.org/0000-0002-0216-7117

${ }^{2}$ Universidade Federal de Minas Gerais. Instituto de Ciências Agrárias - MG http://orcid.org/0000-0003-1549-9054

3Universidade Federal de Minas Gerais. Instituto de Ciências Agrárias - MG http://orcid.org/0000-0003-1144-0880

${ }^{4}$ Universidade Federal de Minas Gerais. Instituto de Ciências Agrárias - MG http://orcid.org/0000-0002-3690-1252

${ }^{5}$ Universidade Federal de Minas Gerais. Instituto de Ciências Agrárias - MG http://orcid.org/0000-0002-5342-7230

${ }^{6}$ Universidade Federal de Minas Gerais. Instituto de Ciências Agrárias - MG http://orcid.org/0000-0001-8980-8599

Universidade Federal de Minas Gerais. Instituto de Ciências Agrárias - MG

http://orcid.org/0000-0001-6714-7996

*Autor para correspondência: handrayfds@hotmail.com
}

Recebido para publicação em 18 de dezembro de 2018. Aceito para publicação em 29 de julho de 2019.

e-ISSN: 2447-6218 / ISSN: 2447-6218 / (C) 2009, Universidade Federal de Minas Gerais, Todos os direitos reservados. 


\section{Introdução}

Os queijos possuem elevado valor cultural, social e econômico em todo o mundo por causa de suas propriedades e particularidades regionais de onde são produzidos. É alimento derivado do leite, produzido por meio de coagulação enzimática, compondo-se de proteínas, cálcio, lipídeos e vitaminas lipossolúveis. Possuem diversos sabores, texturas, aromas, formatos e alto valor nutricional (Benaouadj et al., 2016; Bemfeito et al., 2016; Correia et al., 2014).

Segundo o Instituto Brasileiro de Geografia e Estatística - IBGE (2015), Minas Gerais é o maior produtor de leite no Brasil, contribuindo com aproximadamente $26,6 \%$ do volume produzido no país. O estado é o maior produtor de queijos, destacando-se com uma variedade artesanal na produção (Martins et al., 2015). De acordo com Perin et al. (2015), o queijo Minas é o mais tradicional no estado, sendo produzido por pequenos agricultores e por laticínios.

Segundo a Empresa de Assistência Técnica e Extensão Rural de Minas Gerais - EMATER-MG, aproximadamente 400 toneladas de queijos são comercializadas anualmente em Montes Claros, movimentando a economia da cidade. Por ser de fabricação simples e de baixo custo, o queijo Minas Frescal representa a maioria dos queijos comercializados em bares, mercearias e feiras livres (Montes Claros, 2010).

A caracterização do perfil físico-químico dos queijos da cidade de Montes Claros, tal como é realizado com queijos de outras cidades, é passo importante para se conhecer a realidade dos produtos comercializados e consumidos no município. Sendo assim, o objetivo com este trabalho foi avaliar as características físico-químicas do queijo Minas Frescal comercializados em feiras livres da cidade de Montes Claros, Norte de Minas Gerais.

\section{Obtenção dos queijos e análises físico-químicas}

Foram coletados quatro queijos de cinco diferentes feiras livres totalizando 20 amostras de queijos tipo Minas Frescal comercializados na cidade de Montes Claros ( $16^{\circ} 44^{\prime} 13^{\prime \prime}$ de latitude Sul, $43^{\circ} 51^{\prime} 53^{\prime \prime}$ de longitude Oeste e altitude média de $661 \mathrm{~m}$ ), no Norte do estado de Minas Gerais. As amostras foram adquiridas semanalmente, durante cinco semanas (quatro amostras/ semana/feira livre), sempre ao início do dia. Os queijos foram mantidos nas mesmas condições de venda, sendo transportados em recipientes isotérmicos sob refrigeração e analisados no dia da coleta, no laboratório de Bromatologia do Instituto de Ciências Agrárias da Universidade Federal de Minas Gerais, em Montes Claros.

Foram avaliadas as características físico-químicas referentes a $\mathrm{pH}$, acidez, umidade, proteínas e gorduras, de acordo com os procedimentos analíticos recomendados pela Association of Official Agricultural Chemists - AOAC
(1995). Todas as análises foram realizadas em triplicatas e os resultados expressos em base seca.

As análises foram determinadas da seguinte maneira: I) pH, realizada em potenciômetro (através de medidor de pH Lucadema, modelo LUCA-210), II) acidez, em percentual de ácido lático $(\% \mathrm{~m} / \mathrm{v})$ foi determinada pelo método de titulometria, com hidróxido de sódio N/9 em presença do indicador fenolftaleína, III) proteínas, pelo método Kjeldahl, utilizando fator de correção de 6,38 e IV) gorduras, determinado através da medida do volume de gordura diretamente na escala do butirômetro de Van Gulik (específico para queijos).

\section{Características físico-químicas do queijo Minas Frescal}

Na Tabela 1 observam-se os valores médios obtidos para os teores de umidade, proteínas e gordura que variaram entre 32,62 a $54,06 \% ; 34,21$ a 49,43\% e 41,30 a $58,41 \%$, respectivamente. Embora não mencione valores para a quantidade de proteínas no queijo, de acordo com a Instrução Normativa no 04, de 01 de março de 2004 (Brasil, 2004), que revoga o Regulamento Técnico de Identidade e Qualidade de queijos Minas Frescal, designado pela Portaria no 352, de 04 de setembro de 1997 (Brasil, 1997), o queijo Minas Frescal é queijo semi-gordo e de muito alta umidade. Deste modo, deve apresentar entre 25,0 e $44,9 \%$ de gorduras e não inferior a $55,0 \%$ de umidade. Com os valores obtidos da gordura no extrato seco, apenas quatro amostras encontraram-se em acordo aos padrões estabelecidos. Por outro lado, nenhuma das amostras apresentou conformidade com a legislação quando se observa os valores médios de umidade dos queijos. Silva et al. (2008), ao analisar queijos tipo minas Frescal produzidos por pequenos produtores do município de Guarapuava e região, encontraram valores de 36,40 a $61,67 \%$ de umidade. Por outro lado, Cavalcante et al. (2007), estudando queijos tipo coalho regionais em diferentes tempos de maturação, encontraram valores de 23,12 a $27,70 \%$ de proteínas. Em queijos elaborados com leite de búfala, os teores de gordura de 41,30 a $58,41 \%$ foram superiores aos $21,40 \%$ descritos por Yunes e Benedet (2000) e acima dos 18,30 a $21,2 \%$ referidos por Van Nieuwenhove et al. (2007a; 2007b).

A umidade interfere nas ações metabólicas de microrganismos no produto, trazem consequências no $\mathrm{pH}$, sabor, aroma e composição nutricional do mesmo e está correlacionado ao seu tempo de conservação (Oliveira, 1981). Variações no teor de umidade indicam variações na matéria-prima utilizada, na formação e manuseio da coalhada e no tempo de prensagem do produto, influenciando também sua habilidade de reter gordura (Nassu et al., 2003).

A variação no teor de proteínas está relacionada à proteólise do queijo durante sua conservação (Bynum e Barbano, 1985). De acordo com Singh et al. (2003), 
Características físico-químicas do queijo Minas Frescal comercializados em feiras livres da cidade de Montes Claros, Minas Gerais

parâmetros como umidade, temperatura e tempo de conservação do produto devem ser controlados para evitar a degradação protéica. Estes resultados também podem estar relacionados à falta de uniformização e pa- dronização dos métodos de elaboração dos queijos, pois são produzidos manualmente e/ou através de processo tecnológico artesanal (Queiroga et al., 2009).

Tabela 1 - Composição físico-química de queijos Minas Frescal comercializados em feiras livres no município de Montes Claros, Minas Gerais

\begin{tabular}{|c|c|c|c|c|}
\hline \multicolumn{5}{|c|}{ Amostras de queijos } \\
\hline Umidade (\%) & № & $\%$ & Menor valor & Maior valor \\
\hline $32,00-42,00$ & 5 & 25 & \multirow{4}{*}{$32,62 \pm 0,67$} & \multirow{4}{*}{$54,06 \pm 2,44$} \\
\hline $42,00-52,00$ & 13 & 65 & & \\
\hline$>52,00$ & 2 & 10 & & \\
\hline Total & 20 & 100 & & \\
\hline Gordura no extrato seco $(\%) *$ & № & $\%$ & Menor valor & Maior valor \\
\hline $41,00-49,00$ & 8 & 40 & \multirow{4}{*}{$41,30 \pm 1,09$} & \multirow{4}{*}{$58,41 \pm 0,90$} \\
\hline $49,00-57,00$ & 10 & 50 & & \\
\hline$>57,00$ & 2 & 10 & & \\
\hline Total & 20 & 100 & & \\
\hline Proteína total $(\%)^{*}$ & № & $\%$ & Menor valor & Maior valor \\
\hline $34,00-38,00$ & 9 & 45 & \multirow{4}{*}{$34,21 \pm 1,28$} & \multirow{4}{*}{$49,43 \pm 1,93$} \\
\hline $38,00-42,00$ & 7 & 35 & & \\
\hline$>42,00$ & 4 & 20 & & \\
\hline Total & 20 & 100 & & \\
\hline $\mathrm{pH}$ & № & $\%$ & Menor valor & Maior valor \\
\hline $4,50-5,00$ & 6 & 30 & \multirow{4}{*}{$4,78 \pm 0,04$} & \multirow{4}{*}{$6,14 \pm 0,19$} \\
\hline $5,00-5,50$ & 10 & 50 & & \\
\hline$>5,00$ & 4 & 20 & & \\
\hline Total & 20 & 100 & & \\
\hline Acidez (\% de ácido lático) & № & $\%$ & Menor valor & Maior valor \\
\hline $0,20-0,90$ & 9 & 45 & \multirow{4}{*}{$0,25 \pm 0,03$} & \multirow{4}{*}{$2,78 \pm 0,15$} \\
\hline $0,90-1,60$ & 7 & 35 & & \\
\hline$>1,60$ & 4 & 20 & & \\
\hline Total & 20 & 100 & & \\
\hline
\end{tabular}

Valores expressos por média \pm desvio padrão. *Valores expressos em base seca.

Os valores de $\mathrm{pH}$ na produção queijeira são adotados com o objetivo de realizar controle durante o processamento. $\mathrm{O}$ pH das amostras analisadas variou entre 4,78 e 6,14. Segundo Dias et al. (2016), essa variação pode ocorrer em consequência do tempo e temperatura de armazenamento nos expositores dos locais de venda.

Em relação ao teor de acidez, as amostras apresentaram variação de 0,25 a $2,78 \%$ de ácido lático. Se- gundo Dias et al. (2016), dependendo das condições da temperatura às quais estão expostos, os queijos podem sofrer alterações, tornando-se mais ácidos. Queiroga et al. (2009) afirmam que o padrão de acidez no queijo "Minas Frescal" é facilmente modificado na presença de espécies de microrganismos na cultura lática. Estes podem fermentar a lactose, resultando na transformação em ácido lático e, consequentemente, aumento da acidez. Caruso e Oliveira (1999) salientaram que o processo de 
dessoragem espontânea, ao qual a massa é submetida durante o processo produtivo do queijo "Minas Frescal", pode, em alguma magnitude, eliminar algum conteúdo de lactose do produto, e assim influenciar os valores de acidez.

\section{Conclusão}

Os resultados mostram a falta de padronização das características físico-químicas das amostras de queijos
Minas Frescal analisadas, o que se relaciona, possivelmente, a uma falta de uniformização na matéria prima ou no processamento, e nos métodos de elaboração desse produto, sendo necessária e imprescindível a aplicação de processo tecnológico e/ou padrões específicos, visando à melhoria no controle de qualidade.

\section{Referências}

Association of Official Agricultural Chemists - AOAC. 1995. Official methods of the Association of the Agricultural Chemists. 16. ed. Washington DC, v. 2, 1094 p.

Bemfeito, R. M.; Rodrigues, J. F.; Silva, J. G.; Abreu, L. R. 2016. Temporal dominance of sensations sensory profile and drivers of liking of artisanal Minas cheese produced in the region of Serra da Canastra, Brasil. Journal of Dairy Science, 99: 7886-7897. Doi: 10.3168/jds.2016-11056.

Benaouadj, F; Ziane-Zafour, A. H.; Rebiha, M. 2016. Effects of modified starch and fat on the rheological characteristics of newly formulated processed cheese: use of experimental design method. Journal of Dispersion Science and Technology, 38: 693-698. Doi: 10.1080/01932691.2016.1189833.

Bynum, O. G.; Barbano, M. D. 1985. Whole milk reverse osmosis retentates for cheddar cheese manufacture: Chemical changes during aging. Journal of Dairy Science, 68: 1-10. Doi: 10.3168/jds.S00220302(85)80789-X.

Brasil. Ministério da Agricultura, Pecuária e Abastecimento, 2004. Instrução Normativa n. 04 de 01 de março de 2004. Alteram a Portaria n. 352 de 04 de setembro de 1997. Diário Oficial [da] República Federativa do Brasil, Brasília, 05 (Seção 1). Disponível em: https://www.jusbrasil. com.br/diarios/1431339/pg-36-secao-1-diario-oficial-da-uniao-doude-08-09-1997.

Brasil. Ministério da Agricultura, Pecuária e Abastecimento, 1997. Portaria n. 352 de 04 de setembro de 1997. Regulamento técnico de identidade e qualidade de queijos. Diário Oficial [da] República Federativa do Brasil, Brasília 04 (Seção 1). Disponível em: https:// www.defesa.agricultura.sp.gov.br/legislacoes/portaria-ma-352de-04-09-1997,644.html.

Caruso, E. C.; Oliveira, A. 1999. Quantificação de lactose em queijos minas frescal. Scientia Agricola, 56: 243-246. Doi: 10.1590/S010390161999000100033.

Cavalcante, J. F. M.; Andrade, N. J.; Furtado, M. M.; Ferreira, C. L. L. F.; Pinto, C. L. O.; Elard, E. 2007. Processamento do queijo coalho regional empregando leite pasteurizado e cultura lática endógena. Ciência e Tecnologia de Alimentos, 27: 205-214. Doi: 10.1590/S010120612007000100036.

Correia, P. M. R.; Vitor, A.; Tenreiro, M.; Correira, A. C; Pinto, A; Barracosa, P.; Madanelo, J.; Vacas, M.; Guiné, R. P. F. 2014. Influence of different processing parameters in physical and sensorial properties of Serra de Estrela cheese. Journal of Hygienic Engineering and Design, 8: 135-140. Disponível em: http://repositorio.ipv.pt/bitstream/10400.19/2424/1/ SCAN_JHED_Cheese.pdf.

Dias, B. F.; Ferreira, S. M.; Carvalho, V. S.; Soares, D. S. B. 2016. Qualidade microbiológica e físico-química de queijo minas frescal artesanal e industrial. Revista de Agricultura Neotropical, 3: 57-64. Doi: 10.32404/rean.v3i3.1211.
Instituto Brasileiro de Geografia e Estatística - IBGE. 2015. Produção da Pecuária Municipal. Rio de Janeiro, v. 43, p. 1-49. Disponível em: https://biblioteca.ibge.gov.br/visualizacao/periodicos/84/ppm_2015 v43_br.pdf.

Martins, J. M.; Galinari, E.; Pimentel-Filho, N. J.; Ribeiro Júnior, J. I.; Furtado, M. M.; Ferreira, C. L. L. F. 2015. Determining the minimum ripening time of artisanal Minas cheese, a traditional Brazilian cheese. Brazilian Journal of Microbiology, 46: 219-230, 2015. Doi: 10.1590/ S1517-838246120131003.

Montes Claros. 2010. Prefeitura Municipal de Montes Claros. Queijos artesanais em Montes Claros movimentam a economia da cidade. Disponível em: http://www.montesclaros.mg.gov.br/agencia noticias/2010/fev10/not_18_02_10_0863.php.

Nassu, R. T.; Araújo, R. S.; Guedes, C. G. M.; Rocha, R. G. A. Diagnóstico das condições de processamento e caracterização físico-química de queijos regionais e manteiga no Rio Grande do Norte. Fortaleza: Embrapa Agroindústria Tropical, 2003. 24 p. Disponível em: http://ainfo.cnptia. embrapa.br/digital/bitstream/CNPAT/7823/1/bd_11.pdf.

Oliveira, J. S. Queijo: fundamentos tecnológicos. São Paulo: Secretaria da Indústria, Comércio, Ciência e Tecnologia / Fundação Tropical de Pesquisas e Tecnologia, 1981.

Perin, L. M.; Bello, B. D.; Belviso, S.; Zeppa, G.; Carvalho, A. F.; Cocolin, L.; Nero, L. A. 2015. Microbiota of Minas cheese as influenced by the nisin producer Lactococcus lactis subsp. lactis GLc05. International Journal of Food Microbiology, 214: 159-167. Doi: 10.1016/j. ijfoodmicro.2015.08.006.

Queiroga, R. C. R. E.; Guerra, I. C. D.; Oliveira, C. E. V.; Oliveira, M. E. G.; Souza, E. L. 2009. Elaboração e caracterização físico-química, microbiológica e sensorial de queijo "tipo minas frescal" de leite de cabra condimentado. Revista Ciência Agronômica, 40: 363-372. Disponível em: http://ccarevista.ufc.br/seer/index.php/ccarevista/ article/view/755/354.

Singh, T. K.; Drake, M. A.; Cadwallader, K. R. 2003. Flavor of Cheddar cheese: A chemical and sensory perspective. Comprehensive Reviews in Food Science and Food Safety, 2: 139-161. Doi: https://doi. org/10.1111/j.1541-4337.2003.tb00021.x.

Silva, T. V.; Santos, M.; Takaki, A. M.; Mimura, H. J.; Alvarez, D. C. 2008. Caracterização físico-química de queijos tipo minas Frescal produzidos por pequenos produtores do município de Guarapuava e região. In: SALÃ̃O DE EXTENSÃO E CULTURA. Anais... Unicentro, Paraná, 2008. Disponível em: http://www.unicentro.br/proec/publicacoes/salao2008/.

Van Nieuwenhove, C. P.; Cano, P. G.; Chaia, A. B. P.; González, S. N. 2007a. Chemical composition and fatty acid content of buffalo cheese from Northwest Argentina: effect on lipid composition of mice tissues. Journal of Food Lipids, 14: 232-243. Doi: 10.1111/j.17454522.2007.00082.x 
Características físico-químicas do queijo Minas Frescal comercializados em feiras livres da cidade de Montes Claros, Minas Gerais

Van Nieuwenhove, C. P.; Oliszewski, R.; González, S. N. ; Chaia, A. B. P. 2007b. Influence of bacteria used as adjunct culture and sunflower oil addition on conjugated linoleic acid content in buffalo cheese. Food Research International, 40: 559-564. Doi: 10.1016/j. foodres.2006.08.003.
Yunes, V. M.; Benedet, H. D. 2000. Desenvolvimento experimental de queijo fresco de leite da espécie bubalina. Ciência e Tecnologia de Alimentos, 20: 285-290. Doi: 10.1590/S0101-20612000000300002. 